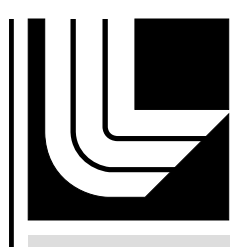

LAWRENCE LIVERMORE N A TIO N A L LABORATORY

VX sampling

Carolyn Koester, William G. Hoppes

February 19, 2010 
This document was prepared as an account of work sponsored by an agency of the United States government. Neither the United States government nor Lawrence Livermore National Security, LLC, nor any of their employees makes any warranty, expressed or implied, or assumes any legal liability or responsibility for the accuracy, completeness, or usefulness of any information, apparatus, product, or process disclosed, or represents that its use would not infringe privately owned rights. Reference herein to any specific commercial product, process, or service by trade name, trademark, manufacturer, or otherwise does not necessarily constitute or imply its endorsement, recommendation, or favoring by the United States government or Lawrence Livermore National Security, LLC. The views and opinions of authors expressed herein do not necessarily state or reflect those of the United States government or Lawrence Livermore National Security, LLC, and shall not be used for advertising or product endorsement purposes.

This work performed under the auspices of the U.S. Department of Energy by Lawrence Livermore National Laboratory under Contract DE-AC52-07NA27344. 


\section{Collecting Wipe Samples for VX Analysis}

\section{Purpose}

This standard operating procedure (SOP) provides uniform procedures for the collection of wipe samples of VX residues from surfaces. Personnel may use this procedure to collect and handle wipe samples in the field. Various surfaces, including building materials (wood, metal, tile, vinyl, etc.) and equipment, may be sampled based on this procedure. The purpose of such sampling is to determine whether or not the relevant surfaces are contaminated, to determine the extent of their contamination, to evaluate the effectiveness of decontamination procedures, and to determine the amount of contaminant that might present as a contact hazard.

\section{Background}

A recent literature review performed on behalf of the United States Environmental Protection Agency concluded that "no overwhelming consensus can be drawn from the current literature on how to collect a wipe sample for the chemical warfare agents, organophosphate pesticides, and other toxic industrial chemicals". ${ }^{1}$ Further, this review suggested that investigative research to fill in the gaps in wipe sampling knowledge should be conducted so that optimized and validated methods can be developed and documented. Currently, there is no accepted procedure for sampling VX from surfaces. However, it is known that there are parameters (e.g. surface area sampled, surface type, wipe material, amount and type of wetting solvent, the amount of pressure and wipe pattern, etc.) that must be stringently controlled in order to provide consistent data. For this reason, it is important to have a set method for the collection of wipe samples. This SOP has been developed based on information provided in literature reports ${ }^{1}$ and procedures developed from current research practices ${ }^{2,3,4}$ and not on verified experimental data. It should be noted that this SOP documents our best recommendation for sampling VX from hard or porous surfaces; but, the procedures suggested here have not been fully tested and validated.

The procedure assumes that the designated area for a wipe sample is a $10 \mathrm{~cm} \mathrm{x} 10 \mathrm{~cm}$ square (or the equivalent of $100 \mathrm{~cm}^{2}$ surface area). Assuming that all VX is removed from a wipe, a final extract volume of $1 \mathrm{~mL}$ after preparation of the wipe sample, analysis by gas chromatography mass spectrometry (as is consistent with procedures of EPA Method $8270^{5}$ ), and instrument detection limit of $0.2 \mathrm{ng} \mathrm{VX}$, method detection limit for VX would be expected to be approximately $2 \mathrm{ng} / \mathrm{cm}^{2}$. 


\section{General Precautions}

\subsection{Safety}

Proper safety precautions must be observed when collecting wipe samples. Personal Protective Equipment (PPE) chosen should be consistent with the expected level of chemical hazard. Databases, such as TOXNET ${ }^{6}$, can be consulted for information regarding potential chemical hazards. When choosing PPE, consider the chemicals that pose specific toxicity or safety concerns and ensure that PPE is compatible with the solvents used for wipe sampling. Specifically, when sampling for VX, a highly-toxic compound, care should be taken to consider the known or suspected concentrations and hazard danger when assessing PPE. All sampling procedures and locations should be reviewed by competent Health and Safety professionals to ensure that appropriate levels of PPE are selected and used for each sampling campaign.

\section{$\underline{3.1 .1 \mathrm{VX}}$}

$\mathrm{VX}$ is a nerve agent. $\mathrm{L}(\mathrm{Ct})_{50}$ values for $\mathrm{VX}$ have been reported at $39-70 \mathrm{mg} * \mathrm{~min} / \mathrm{m}^{3}$. It has been reported that $\mathrm{VX}$ is lethal at $10 \mathrm{mg} * \mathrm{~min} / \mathrm{m}^{3}$ to a $70 \mathrm{~kg}$ human adult inhaling at $15 \mathrm{~L} / \mathrm{min}$. The estimated lethal dose for skin exposure is $6 \mathrm{mg}$. VX is also an acetylcholinesterase inhibitor. RB-ACh $E_{50}$ values of $0.034 \mathrm{mg} / \mathrm{kg}(12 \mathrm{hr})$ and $0.029 \mathrm{mg} / \mathrm{kg}(24 \mathrm{hr})$ have been reported (human, dermal, undiluted liquid). Effects from skin exposure to liquid nerve agent may not develop for up to 18 hours following exposure. Mild symptoms of VX exposure include localized sweating, fasciculations, gastrointestinal effects, and miosis. Symptoms of more severe VX exposure can include sudden loss of consciousness, seizures, apnea, flaccid paralysis, and death.

\subsubsection{Dichloromethane}

Dichloromethane is moderately irritating to skin and eyes and is a probable human carcinogen. Prolonged exposure to high concentrations of dichloromethane has caused reversible central nervous system effects, slight eye irritation, and mortality in several laboratory species.

\subsubsection{Isopropyl alcohol}

Isopropyl alcohol can irritate eyes, mucous membranes, and the respiratory tract. Mild irritation of the eyes, nose and throat was induced in human subjects exposed for 3 to 5 min to $400 \mathrm{ppm}$ of isopropyl alcohol.

\subsection{Procedural Precautions}

Special care must be taken not to contaminate samples. Make sure that sampling containers and tools are clean prior to use and avoid situations that might cause cross-contamination of samples.

Make sure that accurate and complete records of all samples and sampling locations are kept.

Make sure that each sample is properly labeled with a unique sample identifier and that chain-ofcustody documentation for each sample is completed. 


\section{Sampling Considerations}

\subsection{Special Precautions for Trace Contaminant Wipe Sampling}

Wear a clean pair of new gloves each time a different surface is sampled. Don gloves immediately prior to sampling. Make sure that the gloves do not come in contact with the media being sampled. Change gloves any time during sample collection when their cleanliness is compromised.

Use new, certified-clean disposable or non-disposable sampling containers and equipment.

Wipes should be precleaned prior to use.

\subsection{Quality Control}

Equipment blanks should be collected when equipment, such as tongs or tweezers, is cleaned in the field and re-used. This step documents that low-level contaminants were not introduced by sampling tools.

Blanks samples of the wipe material must also be submitted for analysis.

\section{Wipe Sampling Methods}

\subsection{Wipe Preparation}

\section{$\underline{5.1 .1 \quad \text { Wipe Material }}$}

Wipes of various adsorbent materials may be used (cotton, glass fiber filter, etc.). An example of appropriate wipes are 3" x 3" gauze pads (Kendall-Curity, 12-ply, P/N 1903, available from Tyco Healthcare Group LP, Mansfield, MA). It is highly advisable to preclean the wipe material prior to sampling. Various extraction techniques, for example solvent cleaning with Soxhlet extraction or pressurized fluid extraction, may be used to remove contaminants from wipes. At least one of the solvents used for cleaning should be the same as that used by the analytical laboratory to extract the sample. Wipes composed of synthetic material may not acceptable due to potential incompatibilities with solvents used in the wipe sampling process.

\subsubsection{Wipe Solvent}

Wipes should be saturated with a high-purity solvent, for example dichloromethane or isopropanol, prior to sample collection. Ideally, these wipes should be wetted, with a consistent amount of solvent, in the controlled environment of a laboratory prior to use in the field.

Note: Sampling personnel should be aware of hazards associated with the selected solvent and should take precautions, such as choosing appropriate PPE, to prevent any skin contact or inhalation of these solvents. 


\section{$\underline{5.1 .3 \text { Containerization }}$}

After the wipes have been prepared and wetted with the appropriate solvent, they should be placed in a pre-cleaned vial or pre-cleaned, 4-ounce jar. The container should be glass and sealed with a PTFE-lined lid. Do not use plastic containers. The laboratory performing analyses of the wipe samples should be consulted regarding container selection. If the laboratory extracts samples by a technique such as waterbath sonication, it might be possible to select a wipe container such that it can also serve as the extraction vessel. After placing wipes in the appropriate container, ensure that the sample container lid is tightened securely to prevent evaporation of the wetting solvent and to maintain cleanliness of the wipes.

\subsection{Surface Area}

Wipe samples are typically collected from an area measuring $100 \mathrm{~cm}^{2}(10 \mathrm{~cm} \mathrm{x} 10 \mathrm{~cm}$ square). This area may be defined using a disposable template (aluminum foil or thin cardboard can be used), which can be held in place by the sampler or taped in place.

Note: When sampling a surface for VX contamination, there is a potential to transfer contamination to the template, which, depending on the situation, might need to be treated as hazardous waste.

\subsection{Sample Collection Procedures}

The following procedures should be followed when collecting wipe samples. Two gauze pads will be used to wipe a single area.

5.3.1 Remove a prepared wipe from the sample container using cleaned stainless steel tongs, tweezers, or gloved hands. If the wipe appears to be saturated to the point of excessive dripping, squeeze excess solvent from the pad back into the sample container before proceeding.

5.3.2 Using either tongs, tweezers, or gloves, fully open the wipe and prepare to collect a sample.

Note: Because of the high toxicity of VX, best practice is to always use tongs or tweezers to collect a wipe sample.

5.3.3 Sample the surface using an S-shaped wiping pattern and firm pressure. Move the wipe in such a manner as to adequately cover the entire surface (e.g. side to side, and slightly downward). Start at the top, corner of the template and work downward. At the midpoint of the area, a clean side of the wipe should be exposed (fold the wipe so that the "dirty" surface is inside the fold). Wiping of the surface should continue, using an S-shaped pattern and firm pressure, until the bottom of the template is reached. 
5.3.4 Place the wipe, now containing the sample, in a clean vial or jar.

5.3.5 Obtain another precleaned wipe and use it to make a second pass over the surface to be wiped. Perform the wiping as described in Section 5.3.3, except that S-shaped pattern used to wipe the surface the second time should be orthogonal to the direction of the first pass (e.g. start at the upper left corner of the template and move the wipe up and down, working towards the right edge of the template).

5.3.6 Immediately after sampling, the second wipe should be placed in the same sealed, glass container as the first wipe. Tightly close the container lid. Sample collection is now complete.

5.3.7 Place the sample in a cooler with blue ice and prepare for transport to the analysis laboratory. If possible, and to follow best practices, the samples should be kept cool during transport. However, as VX is resistant to degradation, cooled transport is not essential.

\subsection{Data Reporting and Interpretation}

Analytical results for wipe sampling are usually reported as a mass of material present on the wipes that were analyzed. If the laboratory is provided with the area of surface that was wiped, data can be presented as mass of material per surface area (e.g. $\mathrm{ng} / \mathrm{cm}^{2}$ ).

Knowledge about the efficiencies and limitations of wipe sampling is critical in order to correctly interpret and use the results of the data that it provides. Before wipe sampling is performed at a site, it is essential to understand the questions that are to be addressed by sampling efforts and to establish, early-on, that the results produced by wipe sampling will be adequate to answer those questions. The results of a wipe sampling campaign can only be interpreted in the context of meeting preselected study objective(s) and with an understanding that the agent of interest might still reside, in significant quantities, under the surface of the material sampled by wiping.

\section{References}

1. United States Environmental Protection Agency, Office of Research and Development, Washington, DC, 20460, A Literature Review of Wipe Sampling Methods for Chemical Warfare Agents and Toxic Industrial Chemicals, EPA/600/R-07/004, January 2007. Available at http://www.epa.gov/nhsrc/pubs/600r07004.pdf.

2. United States Environmental Protection Agency, Office of Research \& Development, National Homeland Security Research Center, Technology Testing and Evaluation Program, Testing and Quality Assurance Plan for the Evaluation of Wipe Sampling Methods for Collecting Chemical Warfare Agents (CWAs), CWA Degradation Products, and Toxic Industrial Chemicals from Various Surfaces, EPA/600/R-08/079, February 2008. Available at http://www.epa.gov/nhsrc/pubs/600r08079.pdf. 
3. Battelle, Final Report: Testing and Evaluation of Wipe Sampling Methods for Collecting Chemical Warfare Agents (CWAs), CWA Degradation Products, and Toxic Industrial Chemicals from Various Surfaces, August 19, 2008.

4. United States Environmental Protection Agency, Region 4, Science and Ecosystem Support Division, Athens, GA, Wipe (Contaminated Surface Sampling), Standard Operating Procedure SESDPROC-304-R1, November 2007. Available at http://www.epa.gov/Region4/sesd/fbqstp/Wipe-Sampling.pdf.

5. United States Environmental Protection Agency, Method 8270D: Semivolatile Organic Compounds by Gas Chromatography/Mass Spectrometry (GC/MS), Rev. 4, February 2007.

6. Hazardous Substances Data Bank, Toxicology Data Network, National Library of Medicine. Available at http://www.nlm.nih.gov/pubs/factsheets/toxnetfs.html. 